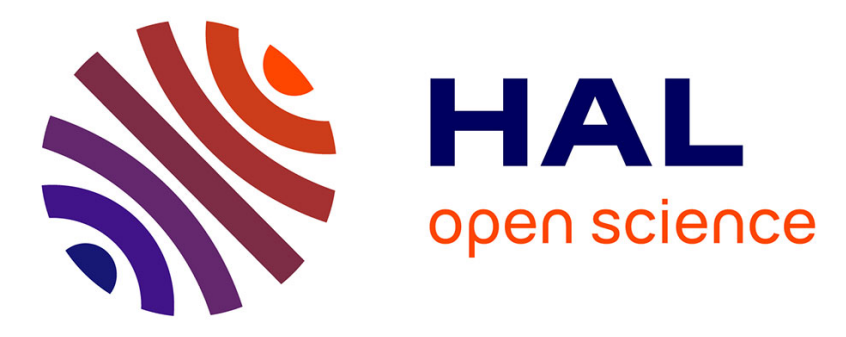

\title{
Growth of Shiga-Toxin producing (STEC) and bovine feces background microflora in various enrichment protocols
}

\author{
A. Vimont, Christine Vernozy-Rozand, M.P. Montet, C. Bavai, B. Fremaux, \\ Marie Laure Delignette-Muller
}

\section{To cite this version:}

A. Vimont, Christine Vernozy-Rozand, M.P. Montet, C. Bavai, B. Fremaux, et al.. Growth of ShigaToxin producing (STEC) and bovine feces background microflora in various enrichment protocols. Veterinary Microbiology, 2007, 123 (1-3), pp.274. 10.1016/j.vetmic.2007.02.003 . hal-00532206

\section{HAL Id: hal-00532206 https://hal.science/hal-00532206}

Submitted on 4 Nov 2010

HAL is a multi-disciplinary open access archive for the deposit and dissemination of scientific research documents, whether they are published or not. The documents may come from teaching and research institutions in France or abroad, or from public or private research centers.
L'archive ouverte pluridisciplinaire HAL, est destinée au dépôt et à la diffusion de documents scientifiques de niveau recherche, publiés ou non, émanant des établissements d'enseignement et de recherche français ou étrangers, des laboratoires publics ou privés. 


\section{Accepted Manuscript}

Title: Growth of Shiga-Toxin producing Escherichia coli (STEC) and bovine feces background microflora in various enrichment protocols

Authors: A. Vimont, C. Vernozy-Rozand, M.P. Montet, C.

Bavai, B. Fremaux, M.-L. Delignette-Muller

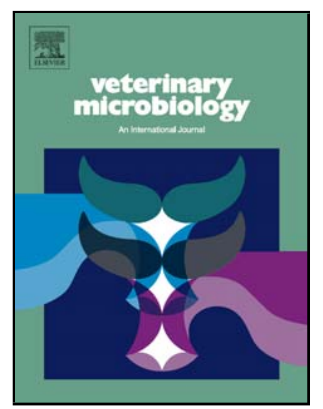

PII: S0378-1135(07)00071-5

DOI: doi:10.1016/j.vetmic.2007.02.003

Reference: VETMIC 3588

To appear in: $\quad$ VETMIC

Received date: 25-9-2006

Revised date: $\quad 1-2-2007$

Accepted date: $\quad$ 2-2-2007

Please cite this article as: Vimont, A., Vernozy-Rozand, C., Montet, M.P., Bavai, C., Fremaux, B., Delignette-Muller, M.-L., Growth of Shiga-Toxin producing Escherichia coli (STEC) and bovine feces background microflora in various enrichment protocols, Veterinary Microbiology (2007), doi:10.1016/j.vetmic.2007.02.003

This is a PDF file of an unedited manuscript that has been accepted for publication. As a service to our customers we are providing this early version of the manuscript. The manuscript will undergo copyediting, typesetting, and review of the resulting proof before it is published in its final form. Please note that during the production process errors may be discovered which could affect the content, and all legal disclaimers that apply to the journal pertain. 
Growth of Shiga-Toxin producing Escherichia coli (STEC) and bovine feces background microflora in various enrichment protocols

A. Vimont ${ }^{1}$, C. Vernozy-Rozand, MP. Montet, C. Bavai, B. Fremaux and M.-L. Delignette-Muller

Unité de Microbiologie Alimentaire et Prévisionnelle, Ecole Nationale Vétérinaire de Lyon, BP 83, 1 avenue Bourgelat, 69280 Marcy l'Etoile, France

Running headline: STEC AND FECES FLORA IN ENRICHMENT

\footnotetext{
${ }^{1}$ Correspondence to : Antoine VIMONT, UMAP, Ecole Nationale Vétérinaire de Lyon, 1 avenue Bourgelat, 69280 Marcy l'Etoile, France. Tel.: +33-4-78-87-25-50; fax: +33-4-7887-25-54 ; e-mail: a.vimont@vet-lyon.fr
} 


\section{Abstract}

Cattle are an important reservoir for STEC and eating food contaminated with faecal material is a frequent source of human STEC infection. It is thus essential to reliably determine the prevalence of STEC contamination in cattle. Currently, different enrichment protocols are used before the detection of Shiga-Toxin producing Escherichia coli (STEC) in faecal samples. However, there have not been any studies performed that have compared the effectiveness of these various enrichment protocols for the growth of non-O157 STEC in faecal samples. The objective of this present study was to characterize the effects of different enrichment factors on the simultaneous growth of the feces background microflora (BM) and two non-O157 STEC strains. The different factors studied were the basal medium (TSB and EC), the effect of novobiocin in the broth $(\mathrm{N}+$ or $\mathrm{N}-)$ and the incubation temperature $\left(37^{\circ} \mathrm{C}\right.$ or $40^{\circ} \mathrm{C}$ ). The BM and STEC growth data were simultaneously fitted by using a competitive growth model. The STEC final levels obtained after $24 \mathrm{~h}$ were higher for the protocols with novobiocin and/or EC compared to the others. However, novobiocin inhibited the growth of one STEC strain. We observed that the addition of novobiocin into broths is not advisable for optimal growth conditions. Moreover, given high BM and low STEC levels often observed in feces, predictions made with the growth model highlighted that false negative results could more likely appear with protocols using TSB without novobiocin than with protocols using EC. In conclusion, the use of EC broth in enrichment protocols seems to be more appropriate for detecting non-O157 STEC from bovine faecal samples. This can help avoid false negative results that cause an underestimation of the STEC prevalence in cattle.

Keywords: Escherichia coli; STEC; bovine feces background microflora; enrichment protocol; competitive growth model. 


\section{Introduction}

Shiga-Toxin producing Escherichia coli (STEC) are a significant public health threat in many industrialized countries (World Health Organization, 1998). Cattle are the primary reservoir for STEC, and human diseases are most often associated with eating food or drinking water contaminated by cattle manure (Bopp et al., 2003).

Several studies were carried out on bovine faecal samples to evaluate STEC prevalence in order to monitor STEC emergence and its implication in faeces-contaminated food and

50 drinking water (Cobbold and Desmarchelier, 2000). Different methods of screening for STEC are currently available (e.g. PCR, IMS, ELISA), and most of them require an enrichment step in order to increase their ability to detect low levels of STEC (Cui et al., 2003).

Several types of enrichment protocols characterized by different factors are currently used for the growth of STEC. The main enrichment protocol factors are the enrichment broth (basal 55 medium), the addition of selective ingredients, the temperature and the duration of the incubation period. Vimont et al. (2006) reported that the Trypticase Soy Broth (TSB) and the E. coli broth (EC) are the most frequently used enrichment broths. They are often supplemented with novobiocin and incubated between 16 to 24 hours at $35-37^{\circ} \mathrm{C}$ for STEC growth. Nevertheless, some authors have also reported an optimal growth temperature of non-

$60 \mathrm{O} 157$ strains around $41^{\circ} \mathrm{C}$ (Gonthier et al., 2001).

However, no study has compared the effectiveness of these various enrichment protocols for the growth of non-O157 STEC in fecal samples (Vimont et al., 2006). Consequently, it appears difficult to compare the prevalence of STEC in cattle published in different studies.

Furthermore, the enrichment step may be difficult to control because of the presence of the background microflora, which may influence the growth of STEC. So far there has been little information concerning the interaction between STEC and feces background microflora. It 
must be emphasized that with a goal of optimizing the enrichment conditions, it is essential to understand the interaction between the two floras during simultaneous growth.

The aim of the present study was to investigate the effect of different enrichment factors on the simultaneous growth of the feces background microflora and two non-O157 (STEC) transformed strains. The different factors studied were the basal medium (TSB and EC), the addition of novobiocin in broth $(\mathrm{N}+$ or $\mathrm{N}-)$ and the incubation temperature $\left(37^{\circ} \mathrm{C}\right.$ and $\left.40^{\circ} \mathrm{C}\right)$. In order to visualize the potential effects of these factors and thus to optimize the enrichment step, a follow up and a modeling of the simultaneous growth of the background microflora and STEC strains were performed.

\section{Materials and methods}

\subsection{Inoculum preparation}

The two STEC strains used in the present study (referred to as Strain 1 and Strain 2), were both isolated from dairy cattle feces during the course of a previous study. These strains did not belong to the serogroup O26, O157, 0111 or O55 and their exact serotypes were not determined. However, they were characterized for the presence of genes coding virulence factors, stx 1 and stx 2 coding the Shiga-Toxins 1 and 2 respectively, as well as eae and ehx coding intimin and EHEC-hemolysin, respectively. Strain 1 and Strain 2 were stx1-, stx2+, $e a e-, e h x$ - and $s t x 1+, s t x 2+, e a e-, e h x+$ respectively. These strains were electroporated in the presence of a plasmid vector pGFPuv (ClonTech) carrying ampicillin resistance and the green fluorescent protein (GFP), according to the protocol described by Delazari et al. (1998). More precisely, the transformation was carried out by setting the electroporation apparatus at 2.5 $\mathrm{kV}$ and $25 \mu \mathrm{F}$ with the pulse controller adjusted to $200 \Omega$. An electrical pulse of $4.7 \mathrm{msec}$ was applied. Point twenty-five $\mu \mathrm{g}$ of GFP-ampicillin resistance plasmid (pGFP) was added to the microcentrifuge tubes containing the bacterial cells. The plasmid and cells were mixed by pipetting, and then transferred into an Invitrogen $0.2 \mathrm{~cm}$ cuvette. With the cuvette in the 
sample chamber, a pulse was applied using the indicated apparatus settings. Aliquot of $0.1 \mathrm{ml}$ of the transformant suspension was spread on Brain Heart Infusion (BHI, 51009, bioMérieux) agar (M3012, Kalys) (BA) plates containing $150 \mu \mathrm{g}$ of ampicillin per ml (Ampicillin Sodium salt, eu0400, Euromedex) (BA-A). The resulting ampicillin resistant transformed colonies showed bright green fluorescent color when viewed with a handheld UV light (Herolab). This transformation was done in order to make the numeration of the two STEC strains among the abundant bovine feces background microflora during the growth follow up experiments easier. Moreover, it must be emphasized that no difference in behaviour was noted between

100 the transformed non-O157 strains and their parental strains. Indeed in a previous study carried out in our laboratory (Fremaux et al., 2006), we had observed the same decline kinetics of the transformed and parental strains in manure microcosms experiments by using the MPN PCR stx method. Moreover, these last authors also showed the stability of the GFP plasmid under selective and non-selective conditions. Prior to the challenge testing, two green fluorescent colonies corresponding to each STEC transformed strain were individually grown in BHI at $37^{\circ} \mathrm{C}$ in order to reach late exponential growth. After 24 hours, the two cultures had yielded a density around $10^{8}$ CFU.ml ${ }^{-1}$ and these precultures were used for the inoculation of bovine faecal samples.

\subsection{Microbiological culture media}

110 In different stages of the study, various microbiological culture media were used. Tryptone Medium (Fluka-Biochemika, Switzerland) was used for the preparation of serial dilutions throughout the experiment. Tryptone Soya Broth (TSB, bioMérieux, Marcy-l'Etoile, France) and E. coli Broth (EC, Fluka-Biochemika, Switzerland) were tested with the addition of $20 \mathrm{mg} .1^{-1}$ novobiocin (TSB.N+, EC.N+) (Sigma, Steinheim, Germany) or without

115 novobiocin (TSB.N-, EC.N-), for the study of the enrichment protocols. PCA (Plate Count Agar) was used as a non-selective medium for the enumeration of the feces background 
microflora (BM). BHI agar with ampicillin (BA-A) $\left(150 \mu \mathrm{g} \cdot \mathrm{ml}^{-1}\right)$ was used as a selective medium for the enumeration of STEC transformed strains visualized by the appearance under a UV light.

\subsection{Feces sample inoculation}

Bovine faecal samples were collected from a dairy farm located in the southeast of France. These samples were mixed together and 25 gram portions of feces were aseptically weighed and deposited in 16 flasks and stored at $4{ }^{\circ} \mathrm{C}$ for less than $24 \mathrm{~h}$ before the experiments. The precultures of the two STEC transformed strains were serially diluted to reach a final 125 concentration of $3 \log _{10}\left(\mathrm{CFU} \mathrm{ml} \mathrm{m}^{-1}\right)$ in fresh Tryptone Medium. One milliliter of each dilution was then individually inoculated into a series of eight different flasks containing the $25 \mathrm{~g}$ portions of feces. After manual homogenization, the 16 flasks ( 8 for each strain) were stored overnight at $4^{\circ} \mathrm{C}$. The content of these 16 flasks was transferred into a stomacher bag in which $225 \mathrm{ml}$ of TSB.N-, or TSB.N+, or EC.N-, or EC.N+ were added according to the growth

130 enrichment protocol. The temperature of each broth was around $25^{\circ} \mathrm{C}$. Hence, a final concentration of roughly 4 CFU of STEC per milliliter was obtained for each stomacher bag.

\subsection{Enrichment protocols}

Growth experiments were carried out with the two STEC strains in the presence of $\mathrm{BM}$ for different enrichment protocols, which were the result of the combination of two temperatures $\left(37^{\circ} \mathrm{C}\right.$ or $\left.40^{\circ} \mathrm{C}\right)$, two basal media (TSB, EC) and the presence or absence of novobiocin $(\mathrm{N}+, \mathrm{N}-)$. For this purpose, the 16 samples obtained at the end of the bovine faecal sample inoculation were stomached for $1 \mathrm{~min}$ and left at room temperature for a $40 \mathrm{~min}$ regeneration step. 


\subsection{Growth monitoring}

140 At each sampling time (every 2 hours for the 8 enrichment protocols), the number of viable cells of BM and STEC was determined by plating $1.0 \mathrm{ml}$ of the appropriate dilutions of the samples onto PCA and $0.1 \mathrm{ml}$ onto BA-A. After incubation, the various PCA and BA-A plates were counted so as to provide the respective BM and STEC growth data for each enrichment protocol.

\subsection{Modelling of individual BM and STEC growth kinetics}

Two growth models were used to fit the observed growth kinetics of both BM and STEC for the eight protocols tested. The first model is a very simple one in two phases with three parameters (Mckellar and Lu, 2004) (model 1). It only describes the exponential and the stationary phases and does not take into account any lag phase:

$y(t)= \begin{cases}y_{0}+\frac{\mu_{\max }}{\ln (10)} \times t & \text { if } t<t_{\max } \\ y_{0}+\frac{\mu_{\max }}{\ln (10)} \times t_{\max } & \text { if } t \geq t_{\max }\end{cases}$

where $\mathrm{y}(t)$ is the bacterial density $\left(\log _{10}\left(\mathrm{CFU} \mathrm{ml} \mathrm{m}^{-1}\right)\right)$ at time $\mathrm{t}$ (hours), $y_{0}$ is the initial bacterial density $\left(\log _{10}\left(\mathrm{CFU} \mathrm{ml} l^{-1}\right)\right), \mu_{\max }$ is the maximum specific growth rate (hours $\left.{ }^{-1}\right)$, and $t_{\max }$ is the time at which the stationary phase begins, i.e. the time at which the maximum

155 bacterial density is reached.

The second model that has four parameters, incorporates a third phase, a lag phase of duration $\lambda$ (hours) (model 2). It has been described with different names and by various authors (McKellar and Lu, 2004). Curves described by this model show an abrupt transition (breakpoint) between the lag and the exponential phases: 


$$
y(t)= \begin{cases}y_{0} & \text { if } t<\lambda \\ y_{0}+\left(\frac{\mu_{\max }}{\ln _{10}}\right) \times(t-\lambda) & \text { if } \lambda \leq t<t_{\text {max }} \\ y_{0}+\left(\frac{\mu_{\text {max }}}{\ln _{10}}\right) \times\left(t_{\max }-\lambda\right) & \text { if } t \geq t_{\text {max }}\end{cases}
$$

\subsection{Global modeling of simultaneous growth of BM and STEC}

A global model (model 3) for the simultaneous growth of BM and STEC is simply defined as using model 1 (without lag phase) for STEC flora along with model 2 (with lag phase) for the background flora. Model 3 is defined by seven parameters ( $y_{0 \text { STEC }}, \mu_{\max \text { STEC }}$, $\left.t_{\max S T E C}, y_{0 B M}, \lambda_{B M}, \mu_{\max B M}, t_{\max B M}\right)$ which may be estimated by two individual fittings of model 1 and model 2 on STEC and BM growth kinetics, or by a global fitting of model 3. A partial model nested in model 3 is also defined in the same way, but assumes a common value of $t_{\max }$ for the two floras (model 4). This final model has only six parameters

$170\left(y_{0 S T E C}, \mu_{\max S T E C}, y_{0 B M}, \lambda_{B M}, \mu_{\max B M}, t_{\max }\right)$ and is based on the hypothesis according to which a potential competition exists between the two floras studied. More precisely, in model 4, the growth of each microflora is assumed to stop as soon as one microflora has reached its maximum density in the enrichment basal medium. This phenomenon has already been described and is commonly referred to as the Jameson effect (Gimenez and Dalgaard, 2004).

\subsection{Statistical methods}

Fits of models to the BM and STEC data were performed by nonlinear regression (Bates and Watts, 1998) by using the least-squares criterion with the function nls of the RSoftware (Ihaka and Gentleman, 1996). Comparisons of nested models (model 2 nested in model 1 and model 4 nested in model 3) were performed using an F test (Bates and Watts, 1998). 


\section{Results}

\subsection{Individual fits of BM and STEC growth kinetics}

Figure 1 demonstrates that Strain 2 did not grow in media in which novobiocin was added $(\mathrm{N}+)$. For the other enrichment protocols, the growth of the STEC strains was not inhibited. The STEC growth kinetics seem to be generally characterized by only two phases; an exponential phase followed by a stationary phase. When the two strains grow, model 1 was used to globally fit the data obtained for the two strains. The choice of a null lag phase for STEC data was justified by the fact that no significant difference was found between model 1 (model in two phases) and model 2 (model in three phases) in terms of the residual sum of 190 squares (RSS) for each protocol $\left(\mathrm{p}_{\mathrm{F} \text { test }}>0.05\right)$.

A similar growth kinetic was obtained with all the enrichment protocols for the background microflora growth. It is characterized by three phases, i.e., a lag phase followed by an exponential and a stationary phase. In all cases, a significantly better fit of the BM growth data was obtained by model 2 than by model $1\left(10^{-5}<\mathrm{p}_{\mathrm{F} \text { test }}<0.03\right)$.

\subsection{Global fits of simultaneous growth of BM and STEC}

Figure 1 shows that for each of the eight protocols studied, the parameters $t_{\max S T E C}$ and $t_{\max B M}$ seem to be very close. Hence, BM and STEC data were globally fitted by model 4 with a common $t_{\max }$ for the two microfloras. No significant difference was found between model 3 (full model) and model 4 (partial model) in terms of RSS for all the protocols

$200\left(\mathrm{p}_{\mathrm{F} \text { test }}>0.05\right)$, except for one protocol (EC.N-.37, $\left.\mathrm{p}_{\mathrm{F} \text { test }}=0.01\right)$. Figure 1 also shows that growth data are well described by model 4 pointing out that the STEC strain growth is stopped as soon as BM reaches its maximal level. Moreover, it is worth noting that this BM maximal level is almost constant from one protocol to another $\left(8.13\right.$ to $\left.8.37 \log _{10}\left(\mathrm{CFU} \mathrm{m}{ }^{-1}\right)\right)$. 


\subsection{Impact of enrichment factors on BM and STEC growth}

Growth inhibition of Strain 2 is observed when novobiocin was added into the enrichment basal media (TSB or EC) which would imply a potential susceptibility of Strain 2 to novobiocin (Fig. 1. and Table 1). For the other protocols, growth of the STEC strains is not inhibited and the STEC initial level ( $y_{0 S T E C}$ ) is not significantly influenced by the enrichment protocol tested where the values vary from 0.13 to $0.71 \log _{10}\left(\mathrm{CFU} \mathrm{m}{ }^{-1}\right)$. On the contrary, the

$210 \mathrm{BM}$ initial level $\left(y_{0 B M}\right)$ appears to decrease by roughly one $\log _{10}$ for the protocols with EC (from 6.15 to $\left.6.41 \log _{10}(\mathrm{CFU} \mathrm{m})^{-1}\right)$ ), compared to those with TSB (from 6.95 to $7.22 \log _{10}$ $\left.\left(\mathrm{CFU} \mathrm{ml} \mathrm{m}^{-1}\right)\right)$. Furthermore, the BM lag time $\left(\lambda_{B M}\right)$ values seem to increase when novobiocin is added in the basal medium especially for protocols with TSB (Fig. 1). Finally, $t_{\max }$ values are higher for the protocols in which selective ingredients (novobiocin and bile salts) are used

215 compared to those using no selective ingredients at $37^{\circ} \mathrm{C}$ or $40^{\circ} \mathrm{C}$ (Fig. 1 and Table 2).

\subsection{Impact of enrichment factors on the maximum STEC level}

It is worth recalling that novobiocin inhibited the growth of Strain 2. However for Strain 1 , the addition of novobiocin creates a delay in the onset of the Jameson effect $\left(t_{\max }\right.$ values are higher for protocols with novobiocin than for protocols without novobiocin). This

220 would allow for a prolonged growth of Strain 1 and thus higher $y_{\max S T E C}$ values regardless of broth and temperature tested $\left(4.08\right.$ to $\left.4.96 \log _{10}\left(\mathrm{CFU} \mathrm{ml}{ }^{-1}\right)\right)$ (Table 1). In the same way, bile salts (present in EC) also delay the onset of the Jameson effect (with an increase of $t_{\max }$ of more than 2 hours in the absence of novobiocin), which implies $y_{\max S T E C}$ values higher for protocols with EC than for protocols with $\mathrm{TSB}$ at $37^{\circ} \mathrm{C}$ or $40^{\circ} \mathrm{C}$. Furthermore when novobiocin is added, the temperature has an impact on the $y_{\max S T E C}$ values regardless of the basal medium. The $y_{\max S T E C}$ values are higher by roughly one $\log _{10}$ for the protocols in which $37^{\circ} \mathrm{C}$ is used than for those in which $40^{\circ} \mathrm{C}$ is used. 


\section{Discussion}

Our results demonstrate a simple competitive interaction between non-O157 STEC and the prevailing background microflora during the enrichment step of faecal samples. Indeed, STEC growth is stopped as soon as BM reaches its maximal level $\left(\sim 8 \log _{10}\right.$ (CFU $\left.\mathrm{ml}^{-1}\right)$ ), which is fairly consistent regardless of the enrichment protocol used.

Natural compound present in feces might also inhibit the growth of STEC. However we hypothesize that their effects is certainly negligible due to their low concentration in the 235 enrichment broth (i.e. $25 \mathrm{~g}$ in $225 \mathrm{ml}$ ).

This present study also shows that the enrichment protocol factors have an impact on the simultaneous growth of BM and STEC strains. More precisely, the protocols with novobiocin and/or EC increased the $t_{\max }$ values, which consequently yielded higher final levels of STEC obtained after $24 \mathrm{~h}$ of enrichment (Fig. 1). Indeed, bile salts included in EC broth delay the onset of the Jameson effect by extending $\lambda_{B M}$, and thus permitted a longer growth for STEC. Nevertheless, the action of novobiocin initially directed against background microflora, could also disadvantage the STEC flora, and could then lead to false negative results. Indeed, our study displayed no detected growth of Strain 2 for the enrichment protocols in which novobiocin was added $(\mathrm{N}+)$. An additional experiment was performed in order to confirm the

245 potential susceptibility of Strain 2 to novobiocin. The transformed Strain 2 and its parental strain were cultured on Muller-Hinton broth containing $20 \mathrm{mg} \cdot \mathrm{ml}^{-1}$ of novobiocin and incubated for $24 \mathrm{~h}$ at $37^{\circ} \mathrm{C}$. No growth of Strain 2 (both the transformed and the nontransformed strains) was observed. This strongly suggests that the non-O157 Strain 2 is susceptible to novobiocin (at 20mg. $1^{-1}$ ). This result is in concordance with those reported by

250 Uemura et al. (2003) who highlighted Minimum Inhibitory Concentrations (MIC) varying from 3.13 to $>100 \mathrm{mg}^{-1}$ for 57 strains of STEC tested. Moreover, Foster et al. (2003) demonstrated the superiority of an enrichment protocol without antibiotics for the isolation of 
E. coli $\mathrm{O} 157: \mathrm{H} 7$ from bovine feces. The addition of novobiocin in enrichment broths appears to be inadequate for the recovery of STEC.

255 The final level of STEC ( $\left.y_{\max S T E C}\right)$ obtained at the end of the enrichment step, is obviously expected to be higher than the detection threshold of the screening method used for the STEC detection. It is worth noting that no method is currently validated for detecting non $\mathrm{O} 157$ STEC in faecal samples. The immunological methods (ELISA, RIA, immunochromatography, and immunomagnetic separation (IMS)) often combined with

260 detection methods, and the genetic methods (like Polymerase Chain Reaction (PCR)) are the main methods used for the detection of STEC. With no prior enrichment step, a minimum concentration of 3.5 to $4.4 \log _{10}$ (CFU of STEC $\mathrm{g}^{-1}$ of sample) is required to allow the detection of the bacteria after the immunomagnetic separation combined with detection methods (IMS-DM) (Gehring et al., 2004). The PCR detection threshold with no prior 265 enrichment step reported in the literature, is $3 \log _{10}\left(\mathrm{CFU} \mathrm{g} \mathrm{g}^{-1}\right)$ (Cui et al., 2003). Figure 1 shows that the protocols with TSB and EC at $37^{\circ} \mathrm{C}$ or $40^{\circ} \mathrm{C}$ without novobiocin, allowed STEC levels (after 24h of incubation) to reach the PCR and the IMS detection thresholds.

Moreover, it must be emphasized that $y_{\max S T E C}$ obviously depends on the initial STEC level in feces $\left(y_{0 \text { STEC }}\right)$. The initial STEC inoculum $\left(0.6 \log _{10}\left(\mathrm{CFU} \mathrm{ml^{-1 }}\right)\right)$ is relatively high in our 270 study because of experimental conditions. Yet, Fukushima et al. (2004) showed that the majority of cattle infected with STEC were low-carriers that contained STEC at a concentration less than $2 \log _{10}\left(\mathrm{CFU} \mathrm{g} \mathrm{g}^{-1}\right)$. Hence, for a STEC concentration in feces of $1 \log _{10}$ $\left(\mathrm{CFU} \mathrm{\textrm {g } ^ { - 1 }}\right)$, and by taking into account the 10 -fold dilution carried out at the beginning of the enrichment protocol (i.e., $25 \mathrm{~g}$ of sample transferred into $225 \mathrm{ml}$ of basal media), this 275 corresponds to a $y_{\text {OSTEC }}$ value around $1 \mathrm{CFU} \mathrm{ml} \mathrm{m}^{-1}$. Predictions made by model 4 with this $y_{\text {OSTEC }}$ realistic value give final STEC levels from 2.3 to $2.4 \log _{10}\left(\mathrm{CFU} \mathrm{ml}{ }^{-1}\right)$ for TSB without 
novobiocin at $37^{\circ} \mathrm{C}$ and $40^{\circ} \mathrm{C}$ after $24 \mathrm{~h}$ of incubation. It is worth noting that the same levels are predicted after 6 hours (the common enrichment duration in the IMS-DM detection protocol of non-O157 STEC and E. coli $\mathrm{O} 157: \mathrm{H} 7$ in food), since the $t_{\max }$ values are lower than 5 hours. When the initial level of contamination by STEC is low, the predictions show that the $y_{\max S T E C}$ values obtained after 6 and $24 \mathrm{~h}$ of enrichment, would be lower than the PCR and IMS-DM detection thresholds. In the same way, predictions made by model 4 with an $y_{\text {OSTEC }}$ value around $1 \mathrm{CFU} \mathrm{ml} l^{-1}$ for $\mathrm{EC}$ without novobiocin at $37^{\circ} \mathrm{C}$ and $40^{\circ} \mathrm{C}$ after a $6 \mathrm{~h}$ enrichment step, give $y_{\max S T E C}$ values (from 2.6 to $2.9 \log _{10}\left(\mathrm{CFU} \mathrm{ml} \mathrm{m}^{-1}\right)$ ) lower than the IMS-

285 DM detection threshold. However given higher $t_{\max }$ values for the protocols with EC, $y_{\max S T E C}$ values after $24 \mathrm{~h}$ of incubation (from 3.2 to $3.4 \log _{10}\left(\mathrm{CFU} \mathrm{ml} \mathrm{m}^{-1}\right)$ ) would reach the PCR detection threshold and get closer to the IMS-DM detection threshold.

Given the high BM level observed in our fecal bovine samples, the $t_{\max }$ values for protocols with TSB.N- (37 and $\left.40^{\circ} \mathrm{C}\right)$ are therefore low ( $<5$ hours). In this case, it is not useful to increase the time beyond 5-6 hours and predictions showed that false negative results could be obtained when the STEC level of contamination is low. However, the predictions highlight that the protocols with EC.N- seem to be more effective than the protocols with TSB.N- for the enrichment of low STEC contamination levels because the $t_{\max }$ values for EC.N- are higher ( $>2.5$ hours) than those for TSB.N- (Table 2).

295 In several studies fecal samples have been used to report prevalence of STEC in cattle. The percentage of STEC in cattle feces ranged from 6\% in an American study (Cray et al., 1996) to $71 \%$ in a French study (Pradel et al., 2000). The difference of prevalence between countries could be due to different reasons (e.g. different samples sizes, various detection methods...), some of which were discussed in the present study. Indeed, we have demonstrated that the 
current enrichment protocols are sometimes inadequate. In addition, some use novobiocin that may inhibit the growth of the target STEC strain, and other protocols may be insufficient to enable a low initial level of the target strain to reach detection threshold because of the competition with background microflora. Yet, in winter low levels of STEC are excreted (Besser et al., 1997) and potential underestimation of the STEC percentage in cattle could certainly be made.

It will be necessary to perform additional experiments with more bovine faecal samples (from different cattle), various STEC serotypes and STEC stressed cells in order to confirm the present results and especially the effectiveness of enrichment protocols with EC broth.

\section{Acknowledgements}

310 We thank Mrs. Ammara Beddiaf for preparation of part of the experiment. We thank Mrs. Marie Cornu and Mrs. Valérie Livrelli for their constructive advice, and Mr. Richard Sullivan for his help with English. This work was supported by the French Food Safety Agency (AFSSA; Agence Française de Sécurité Sanitaire des Aliments, Maisons-Alfort, France).

\section{References}

Armstrong, G.L., Hollingsworth, J., Morris, J.G., 1996. Emerging foodborne pathogens: Escherichia coli $\mathrm{O} 157: \mathrm{H} 7$ as a model of entry of a new pathogen into the food supply of the developed world. Epidemiol. Rev. 18, 29-51.

Bates, D., Watts, D., 1998. Non linear regression and its applications. John Wiley \& Sons Inc, New York.

Besser, T.E., Hancock, D.D., Pritchett, L.C., McRae, E.M., Rice, D.H., Tarr, P.I., 1997. Duration of detection of fecal excretion of Escherichia coli $\mathrm{O} 157: \mathrm{H} 7$ in cattle. J. Infect. Dis. 175, 726-729. 
Beutin, L., Montenegro, M.A., Orskov, I., Orskov, F., Prada, J., Zimmermann, S., Stephan, R, 1989. Close association of verotoxin (Shiga-like toxin) production with enterohemolysin production in strains of Escherichia coli. J. Clin. Microbiol. 27, $2559-2564$.

Bopp, D., Sauders, B., Waring, A., Ackelsberg, J., Dumas, N., Braun-Howland, E., Dziewulski, D., Wallace, B., Kelly, M., Halse, T., Musser, K., Smith, P., Morse, D., Limberger, R., 2003. Detection, isolation, and molecular subtyping of Escherichia coli O157:H7 and Campylobacter jejuni associated with a large waterborne outbreak. J. Clin. Microbiol. 41, 174-180.

Bouvet, J., Vernozy-Rozand, C., 2000. Méthodes génétiques de détection des Escherichia coli verotoxiques (STEC) et de E. coli O157:H7 dans les aliments. Rev. Med. Vet. 151, 907-914.

Cobbold, R., Desmarchelier, P., 2000. A longitudinal study of Shiga-toxigenic Escherichia coli (STEC) prevalence in three Australian diary herds. Vet. Microbiol. 71, 125-137.

Cray, W.C., Jr., Thomas, L.A., Schneider, R.A., Moon, H.W., 1996. Virulence attributes of Escherichia coli isolated from dairy heifer feces. Vet. Microbiol. 53, 369-374.

340 Cui, S., Schroeder, C., Zhang, D., Meng, J., 2003. Rapid sample preparation method for PCRbased detection of Escherichia coli O157:H7 in ground beef. J. Appl. Microbiol. 95, $129-134$.

Delazari, I., Iaria, S.T., Riemann, H., Cliver, D.O., Jothikumar, N., 1998. Removal of Escherichia coli $\mathrm{O} 157: \mathrm{H} 7$ from surface tissues of beef carcasses inoculated with wet and dry manure. J. Food Prot. 61, 1265-1268.

Dodd, C., Sanderson, M., Sargeant, J., Nagaraja, T., Oberst, R., Smith, R., Griffin, D., 2003. Prevalence of Escherichia coli $\mathrm{O} 157$ in cattle feeds in Midwestern feedlots. Appl. Environ. Microbiol. 69, 5243-5247. 
Duffy, G., Whiting, R.C., Sheridan, J.J., 1998. The effect of a competitive microflora, pH and temperature on the growth kinetics of Escherichia coli O157:H7. Food microbiol. 16, 299-307.

Foster, G., Hopkins, G., Gunn, G., Ternent, H., Thomson-Carter, F., Knight, H., Graham, D., Edge, V., Synge, B., 2003. A comparison of two pre-enrichment media prior to immunomagnetic separation for the isolation of E. coli $\mathrm{O} 157$ from bovine faeces. J. Appl. Microbiol. 95, 155-159.

Fremaux, B., Delignette-Muller, M.L., Prigent-Combaret, C., Gleizal, A., Vernozy-Rozand, C., 2006. Growth and survival of non O157:H7 Shiga toxin-producing Escherichia coli (STEC) in cow manure. J. Appl. Microbiol. In press

Fukushima, H., Gomyoda, M., 1999. Hydrochloric acid treatment for rapid recovery of Shiga toxin-producing Escherichia coli $\mathrm{O} 26, \mathrm{O} 111$ and $\mathrm{O} 157$ from faeces, food and environmental samples. Zentralbl. Bakteriol. 289, 285-299.

Fukushima, H., Seki, R., 2004. High numbers of Shiga toxin-producing Escherichia coli found in bovine faeces collected at slaughter in Japan. FEMS Microbiol. Lett. 238, 189-197.

365 Gehring, A.G., Irwin, P.L., Reed, S.A., Tu, S.I., Andreotti, P.E., Akhavan-Tafti, H., Handley, R.S., 2004. Enzyme-linked immunomagnetic chemiluminescent detection of Escherichia coli O157:H7. J. Immunol. Methods. 293, 97-106.

Gimenez, B., Dalgaard, P., 2004. Modelling and predicting the simultaneous growth of Listeria monocytogenes and spoilage micro-organisms in cold-smoked salmon. J. Appl. Microbiol. 96, 96-109.

Gioffré, A., Meichtri, L., Miliwebsky, E., Baschkier, A., Chillemi, G., Romano, M., Estani, S.S., Cataldi, A., Rodriguez, R., Rivas, M., 2002. Detection of Shiga toxin-producing 
Escherichia coli by PCR in cattle in Argentina. Evaluation of two procedures. Vet. Microbiol. 87, 301-313.

375 Gonthier, A., Guérin-Faublée, V., Tilly, B., Delignette-Muller, ML., 2001. Optimal growth temperature of O157 and non-O157 Escherichia coli strains. Lett. Appl. Microbiol. $33,352-356$.

Griffin, P., Tauxe, RV., 1991. The epidemiology of infections caused by Escherichia coli O157:H7, other enterohemorrhagic E. coli, and the associated hemolytic uremic syndrome. Epidemiol. Rev. 13, 60-98.

Hussein, H.S., Sakuma, T., 2005. Prevalence of Shiga toxin-producing Escherichia coli in dairy cattle and their products. J. Dairy Sci. 88, 450-465.

Ihaka, R., Gentleman, R., 1996. R: a language for data analysis and graphics. J. Comp. Graph. Stat. 5, 299-314.

385 Lionberg, W., Restaino, L., Frampton, E., Barbour, W., 2003. Efficacy of enrichment broths in the recovery of freeze-injured Escherichia coli $\mathrm{O} 157: \mathrm{H} 7$ in inoculated ground beef by PCR. J. Food Prot. 66, 1911-1915.

McDonough, P., Rossiter, C., Rebhun, R., Stehman, S., Lein, D., Shin, S., 2000. Prevalence of Escherichia coli O157:H7 from cull dairy cows in New York state and comparison of culture methods used during preharvest food safety investigations. J. Clin. Microbiol. 38, 318-322.

McKellar, R.C., Lu, X., 2004. Primary models. In modeling microbial responses in food. Eds. McKellar, R.C. and Lu, X. CRC Press. Boca Raton, Florida.

Osek, J., 2002. Rapid and specific identification of Shiga toxin-producing Escherichia coli in 395 faeces by multiplex PCR. Lett. Appl. Microbiol. 34, 304-310.

Phan, Q., McCarthy, T., Mschar, P., Welles, C., Howard, R., Rabatsky-Ehr, T., Hadler, J., 2002. Epidemiology of Shiga Toxin-producing Escherichia coli (STEC) infections in 
Connecticut. 3rd International Conference on Emerging Infectious Diseases, Atlanta Georgia-USA.

400 Pradel, N., Livrelli, V., De Champs, C., Palcoux, J.B., Reynaud, A., Scheutz, F., Sirot, J., Joly, B., Forestier, C., 2000. Prevalence and characterization of Shiga toxin-producing Escherichia coli isolated from cattle, food, and children during a one-year prospective study in France. J. Clin. Microbiol. 38, 1023-1031.

Tamplin, M., 2002. Growth of Escherichia coli O157:H7 in raw ground beef stored at 10 degrees $\mathrm{C}$ and the influence of competitive bacterial flora, strain variation, and fat level. J. Food Prot. 65, 1535-1540.

Tarr, P., 1995. Escherichia coli O157:H7: clinical, diagnostic, and epidemiological aspects of human infection. Clin. Infect. Dis. 20, 1-8.

Tutenel, A., Pierard, D., Vandekerchove, D., Hoof, J.V., Zutter, L.D., 2003. Sensitivity of methods for the isolation of Escherichia coli $\mathrm{O} 157$ from naturally infected bovine faeces. Vet. Microbiol. 94, 341-346.

Uemura, R., Sueyoshi, M., Nagayoshi, M., Nagatamo, H., 2003. Antimicrobial susceptibilities of Shiga Toxin-Producing Escherichia coli Isolates from pigs with Edema disease in Japan. Microbiol. Immunol. 47, 57-61.

415 Vimont, A., Vernozy-Rozand, C., Delignette-Muller, M.L., 2006. Isolation of E. coli O157:H7 and STEC non-O157 in different matrices: review of the most commonly used enrichment protocols. Lett. Appl. Microbiol. 42, 102-108.

Vold, L., Holck, A., Wasteson, Y., Nissen, H., 2000. High levels of background flora inhibits growth of Escherichia coli O157:H7 in ground beef. Int. J. Food Microbiol. 56, 219225. 
World Health Organization, 1998. Zoonotic non-O157 Shiga toxin-producing Escherichia coli (STEC) : report of a WHO Scientific Working Group Meeting. World Health Organization-Berlin. Berlin, Germany. 


\section{FIGURE CAPTIONS}

Fig. 1. Simultaneous growth kinetics of the two non-O157 STEC transformed strains and background microflora obtained for the eight protocols and theoretical curves obtained by fitting of model 4. O, Strain 1; $\Delta$, Strain 2. The grey color (dots and curves) represents

430 background flora data sets and the black color represents STEC data sets. The $t_{\max }$ values are represented by the vertical dotted lines. 
Table 1 The maximum concentration of STEC strains 1 and 2 after each enrichment protocol, calculated as the average of the bacterial counts measured after $12 \mathrm{~h}$

435

440

\begin{tabular}{lcc}
\hline Protocols & Strain 1 & Strain 2 \\
\hline TSB.N-.40 & 2.97 & 3.03 \\
TSB.N-.37 & 2.90 & 3.19 \\
TSB.N+.40 & 4.08 & $\mathrm{ND}^{\dagger}$ \\
TSB.N+.37 & 4.96 & $\mathrm{ND}$ \\
\hline EC.N-.40 & $3^{*}$ & 4.16 \\
EC.N-.37 & 3.69 & 3.39 \\
EC.N+.40 & 4.27 & $\mathrm{ND}$ \\
EC.N+.37 & 4.96 & $\mathrm{ND}$ \\
\hline
\end{tabular}

445

* value obtained at $24 \mathrm{~h}$ (not calculated as an average, observations lacking for experimental reasons)

${ }^{\dagger}$ Not Detected $\left(<4\right.$ CFU.ml $\left.{ }^{-1}\right)$ 
Table $2 t_{\max }$ obtained for each enrichment protocol

\begin{tabular}{ccc}
\hline Protocols & $t_{\max }(\mathrm{h})$ & $95 \%$ confidence intervals of the $t_{\max }$ \\
\hline TSB.N-.40 & 4.18 & $3.86-4.51$ \\
TSB.N-.37 & 4.93 & $4.46-5.39$ \\
TSB.N+.40 & 8.1 & $7.68-8.52$ \\
TSB.N+.37 & 8.89 & $8.31-9.46$ \\
EC.N-.40 & 6.95 & $6.06-7.84$ \\
EC.N-.37 & 7.34 & $6.67-8.01$ \\
EC.N+.40 & 8.83 & $8.11-9.56$ \\
EC.N+.37 & 10.16 & $9.62-10.69$ \\
\hline
\end{tabular}

470

475

480 
